\title{
Ceramic Laminate Veneers for Reestablishment of Esthetics in Case of Lateral Incisor Agenesis
}

\author{
Geórgia Silva, ${ }^{1}$ Ana Cristina Normandes, ${ }^{1}$ Edson Barros Júnior ${ }^{(D)},{ }^{2}$ Joyce Gatti (D), ${ }^{3}$ \\ Kalena Maranhão $\left(\mathbb{D},{ }^{3}\right.$ Ana Cássia Reis $\left(\mathbb{D},{ }^{3}\right.$ Fernanda Jassé, ${ }^{3}$ Lucas Moura, ${ }^{3}$ and \\ Thaís Barros $\mathbb{D}^{3}$ \\ ${ }^{1}$ School Superior of Amazonia (ESAMAZ), Belém, PA, Brazil \\ ${ }^{2}$ College São Leopoldo Mandic (SLMANDIC), Belém, PA, Brazil \\ ${ }^{3}$ School of Dentistry, School Superior of Amazonia (ESAMAZ), Belém, PA, Brazil
}

Correspondence should be addressed to Ana Cássia Reis; anacassiareis@gmail.com

Received 8 August 2017; Accepted 23 October 2017; Published 17 January 2018

Academic Editor: Daniel Torrés-Lagares

Copyright (c) 2018 Geórgia Silva et al. This is an open access article distributed under the Creative Commons Attribution License, which permits unrestricted use, distribution, and reproduction in any medium, provided the original work is properly cited.

\begin{abstract}
The increasing demand of patients looking for esthetics has resulted in the development of several techniques to restore anterior teeth. Conservative treatments should always be the first therapeutic option for the solution of aesthetic problems involving morphological changes and usually provide the result that the patient expects. In this context, ceramic laminate veneers, also known as "contact lenses," are capable to provide an extremely faithful reproduction of natural teeth with great color stability and periodontal biocompatibility. Minimal or no preparation veneers are heavily advertised as the answer to patients' cosmetic needs, when properly indicated by the dentist. This paper reports a clinical case where lateral incisor agenesis was aesthetically corrected using ceramic laminates.
\end{abstract}

\section{Introduction}

Agenesis is defined as a numerical anomaly that expresses the lack of development of one or more teeth, occurring in approximately $25 \%$ of the population, and can affect deciduous and permanent dentitions resulting from a dental blade disorder which prevents the formation of the dental germ. It may also be referred to as partial anodony, hypodontia, or oligodontia [1-12].

In the Brazilian population, agenesis affects between $2 \%$ and $5 \%$ of people depending on the affected tooth and excluding the third molars (wisdom tooth) that ranges around $20 \%$ to $30 \%$. According to Santos [13], the most frequently observed agenesis, excluding third molars, is the one that affects the maxillary lateral incisors (ILS) (37.1\%), followed by the mandibular second premolars $(32.26 \%)$ and maxillary second premolars (17.54\%).
The esthetic and functional alteration that the agenesis of ILS can provoke is quite relevant, being a concern factor, not only for the patients with the anomaly but also for the dentists responsible for planning the case. This anomaly can generate a change between the dental arches; being an important factor predisposing to malocclusions, it alters the function of the stomatognathic system, besides causing a great aesthetic discomfort, which is the main complaint of the patient [1-12].

Several treatments are suggested in the literature in cases of the absence of one or more ILS. The options range from no treatment or even two possibilities of clinical interventions (1) to create adequate space for inclusion of the missing tooth/teeth [14] or (2) to close the available space in the dental arch, providing the contact of the central incisor with canine, associated to the reanatomization of the canine, transforming it into a lateral incisor [11, 15, 16]. 
The decision during the treatment planning implies in the identification of alternative procedures, the prediction of the relative probabilities in favor of the long-term desired result, and evaluation of the cost-risk-benefit relation of each alternative [11]. The decision should be understandable to the patient or caregivers and better meet the needs of the patient. Many challenges are involved in obtaining and maintaining optimal results [17-19].

With the evolution of restorative materials and adhesion procedures, ceramic laminates have been used in corrections and dental reconstructions with a high predictability of success, especially because they require less wear or, in many cases, no wear, preserving a greater amount of sound dental structure, contributing to pulp and periodontal health $[20,21]$. Besides these advantages, the aesthetic treatment using ceramic laminates also presents other ones such as biocompatibility, color stability, and good optical properties, enabling the dental reestablishment with biomechanical characteristics similar to natural teeth [22-25].

The proper selection of a ceramic system for certain clinical situations may provide greater longevity of these restorations. Although most of these systems promote good esthetic results, some are better suited for anterior regions because of the greater translucency of the material. Several criteria can be used by the professional to select the most appropriate ceramic system, such as esthetics, marginal adaptation, biocompatibility, resistance, cost, and ease of manufacturing [26-32].

Therefore, the objective of this work is to describe the esthetic treatment of a patient affected by ILS agenesis (12 and 22), by means of ceramic laminate veneers.

\section{Diagnosis and Etiology}

2.1. Clinical Case. A 28-year-old male patient was concerned about the esthetic of his smile. After the anamnesis and clinical and radiographic examinations, it was verified that the patient presented agenesis of dental elements 12 and 22; elements 13 and 23 occupied the lateral incisors' space; and elements 14 and 24 were rotated (Figure 1).

2.1.1. Treatment Plan. After case evaluation by the clinician, the first option of a treatment plan proposed to the patient was correction of the positioning of the canines and premolars by means of orthodontic movement and, later, implantation of the lateral incisors. However, this option was not accepted by the patient who was not interested in undergoing the surgical procedure.

The second treatment planning option proposed was reanatomization of elements $14,13,11,21,23$, and 24 , by means of the preparation of ceramic laminates in order to better harmonize the patient's smile. All the advantages and disadvantages of the treatment were exhaustively explained to the patient who, after understanding the proposed treatment, agreed with the execution of the procedure.

2.1.2. Diagnostic Waxing. The first clinical step of the treatment was to perform molding using condensation silicone Zetaplus (Zhermack) to study the case. After the model

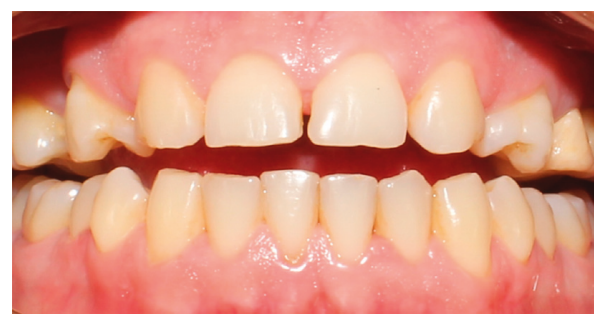

Figure 1: Preoperative view of the patient's smile.

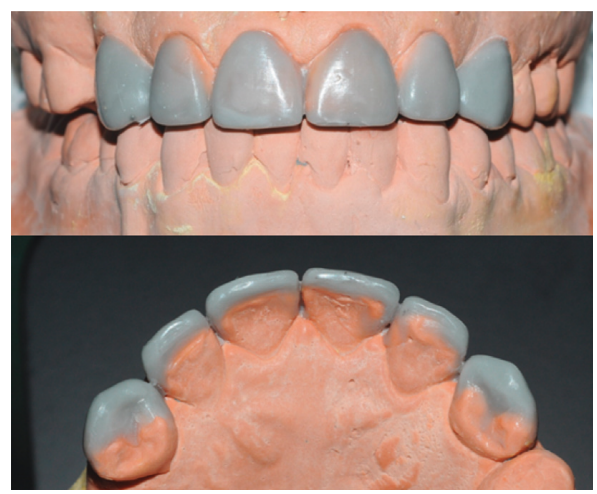

FIgURE 2: Diagnostic waxing proposed to reanatomize and provide harmony to the patient's smile.

was obtained, elements 13 and 23 were waxed so that the anatomy was as close as possible to the anatomy of upper lateral incisors. The elements 14 and 24 had their rotation "corrected" and received anatomical characteristics of canines.

According to the principles of proportionality and in order to maintain the smile harmony, elements $14,13,11,21$, 23 , and 24 were enlarged both in the mesiodistal and in the cervicoincisal dimensions. Figure 2 shows the proposed waxing model.

2.1.3. Tooth Whitening and Mock-Up. In order to optimize the aesthetic result of the case, the patient underwent an in-office whitening session. Three 15-minute applications of Whiteness HP 35\% (FGM) were performed. No sensitivity was reported by the patient, and the result obtained (Figure 3) was considered satisfactory (Initial color: color A3/Final color: A2-VITA Classical scale).

After 7 days, the mock-up was performed so that the patient could visualize the simulation of the proposed treatment, as well as to allow us to detect the need for corrections in the diagnostic waxing.

The waxed model was duplicated, and a silicone tray was made using a vacuum plasticizer, which allowed to "transfer" the proposed waxing to the patient's mouth (Figure 4).

A bisacrylic resin (Protemp 4-3M ESPE) was used to simulate the proposed aesthetic resolution. The tray was loaded with the material (Figure 5) and taken into position after 40 seconds from the start of loading.

After 1 minute, the tray was removed. The "mock-up" was finished with a 15C scalpel blade, 3195 F and FF diamond burs and abrasive papers. Figure 6 illustrates the result obtained after mock-up. 


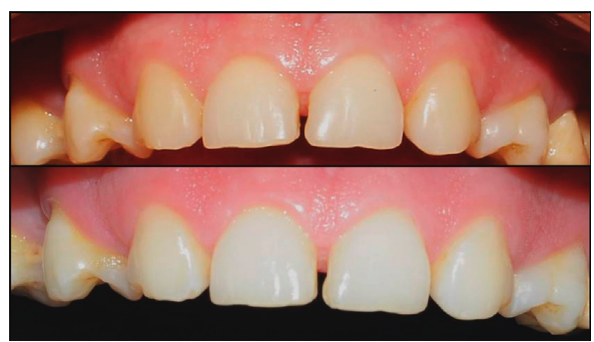

Figure 3: Result obtained after bleaching.

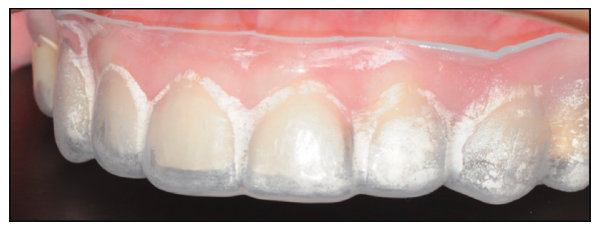

FIGURE 4: Silicone tray in position.

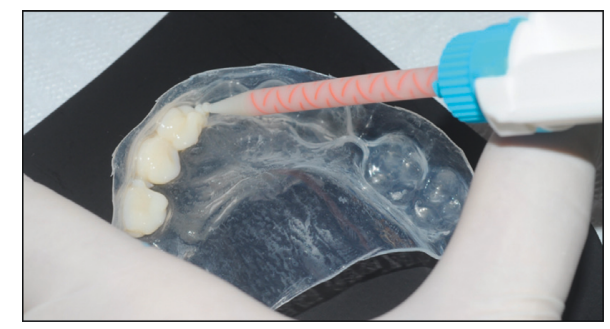

FIgURE 5: Silicone tray being loaded with Protemp 4 (3M ESPE).

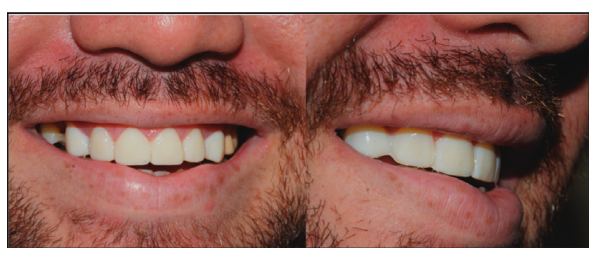

FIGURE 6: Result obtained with mock-up.

The patient was extremely satisfied with the result of the simulation; however, clinically, a small overconfiguration was observed in the mesial region of element 24 . The overconfiguration was corrected in the waxed model so that the patient did not present any periodontal changes after finishing of treatment.

2.1.4. Selective Wear. After approval by the patient and adjustments made in the diagnostic waxing, the phase of selective wear was started. It was decided to perform these abrasions only in the areas that presented a thin layer of wax in the waxed model, thus guaranteeing a satisfactory thickness in the future ceramic laminate.

The regions that received selective wear were cervicalmesial of element 13, vestibular-mesial of elements 11 and 21, and cervical-mesial of 23, as shown in Figure 7.
All wear was performed using the $4138 \mathrm{~F}$ (Poul Sorense) diamond bur and polished with Optimize (TDV) abrasive rubbers and Polimax Felt Disc (TDV). No cervical termination region was established. Figure 8 shows the clinical situation after finishing the wear and polishing steps.

2.1.5. Impressions and Color Selection. In sequence, the impression of preparations was performed using addition silicone (Express-3M ESPE) by means of the double mixing technique and without gingival clearance (Figure 9). The antagonistic arch was molden using alginate (Hydrogun5Zhermarck), and an interocclusal record was taken using a wax plate 7. Color 1M2 was selected using the VITA 3D Master scale. The laboratory technician was informed that the "preparation" was all in enamel.

2.1.6. Laboratory Steps. The work model was screwed up to obtain a better adaptation of the laminates on the proximal faces (Figure 10). A silicone wall (Zetalabor-Zhemarck) was made based on the waxed model, in order to allow a better visualization of the thickness of the prosthetic pieces (Figure 11).

The porcelain used was the VITA PM-9, which is a feldspathic pottery reinforced by Leucita. The laminates are made by the lost wax technique, in which the ceramic is injected under high temperature $\left(1000^{\circ} \mathrm{C}\right)$ and pressure $(4,7$ bar) in a coating mold. Figure 12 shows the steps of lost of wax (a), positioning of the mold (b), and inclusion in the coating material (c).

To remove the newly injected ceramic from the coating mold, blasting with glass beads with a $50 \mu \mathrm{m}$ granulation and a pressure of 2 bar (Figure 13(a)) was used. After the coating is completely removed, the injection channel is separated with a diamond disc, followed by adjustments, finishing, and polishing (Figures 13(b) and 13(c)).

2.1.7. Cementation. The ceramic laminates were tested on the patient to check and adjust the proximal contact points. For cementation, a photoactivated resin cement (AllCem Veneer-FGM) was used, which has a try-in system-it is a color proof paste that mimics the colors of the resin cement after light curing. The selected color for the cement was A3. The adhesive protocol was minutely performed in the dental structure: conditioning with $37 \%$ phosphoric acid (Condact 37-FGM) for $30 \mathrm{~s}$, followed by washing for $60 \mathrm{~s}$ and removal of moisture. After performing this step, gingival clearance (Figure 14) using retractor wire (Retractor \# 00-FGM) was performed to ensure that there is no excess adhesive and/or cement in the gingival sulcus region. Then the adhesive system (Adper SingleBond-3M ESPE) followed by photopolymerization for $10 \mathrm{~s}$ were applied.

The inner surfaces of ceramic laminates were conditioned with $10 \%$ hydrofluoric acid (Condac 10\%-FGM) for $20 \mathrm{~s}$, followed by rinsing with copious amounts of water, drying, and, afterwards, the application of three layers of silane (Prosil-FGM). After silane evaporation, the adhesive system Adper Single Bond 2 (3M ESPE) was applied. 


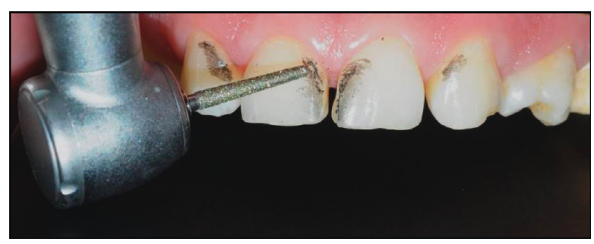

Figure 7: Regions selected to receive selective wear.

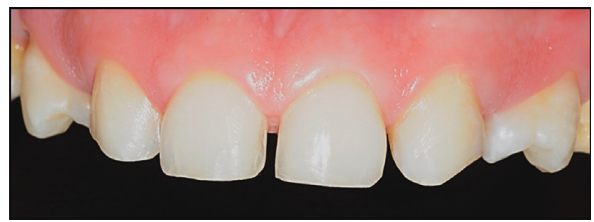

FIGURE 8: Clinical situation after finishing the wear and polishing steps.

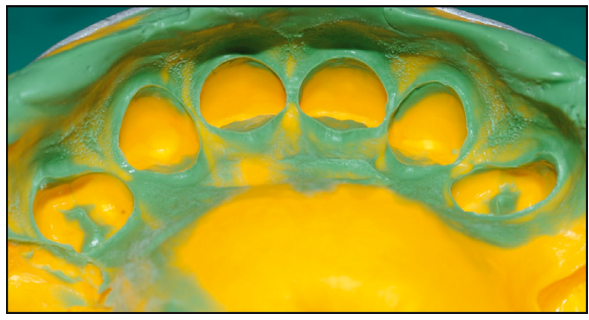

FIgURE 9: Impression of preparations made with addition silicone (Express-3M ESPE).

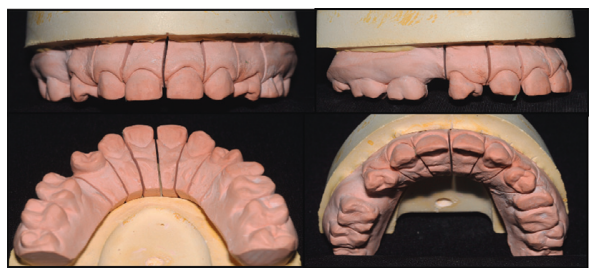

FIgURE 10: Cutting of the plaster work model.

The cement was applied on the cementation surfaces of ceramic laminates. After that, veneers were positioned with cement until its excess had overflowed (Figure 15).

The cementation sequence adopted was upper central incisors, followed by the premolars and, finally, the canines. After the cementation, the finishing steps were accomplished with fine-grained and extrafine diamond burs, followed by polishing with abrasive rubbers (Exa-cerapol-Edenta). The final result obtained is illustrated in Figure 16.

\section{Discussion}

Aesthetics has been increasingly required in today's dentistry. With the increase of access to information, through the Internet, books, and magazines, the population becomes more and more demanding.

Therefore, aesthetics should be closely associated with the patient's wishes, respecting the principles of smile harmony,

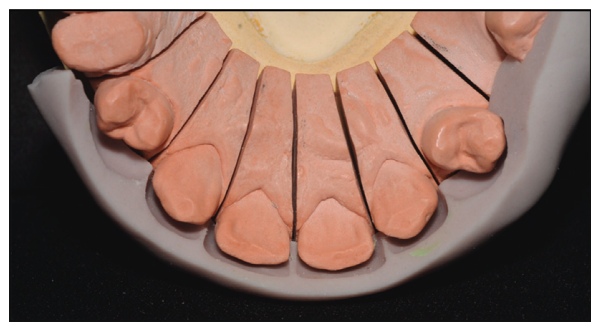

FIGURE 11: Silicone wall in position. The thicknesses of the ceramic laminates can be observed.

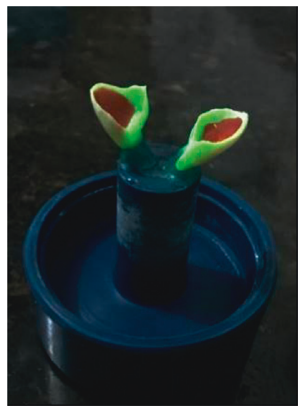

(a)

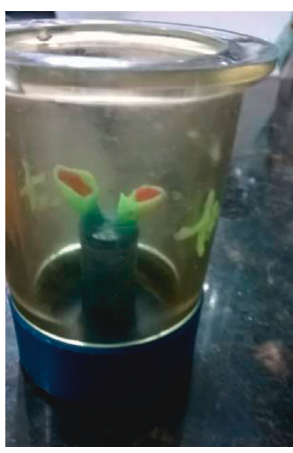

(b)

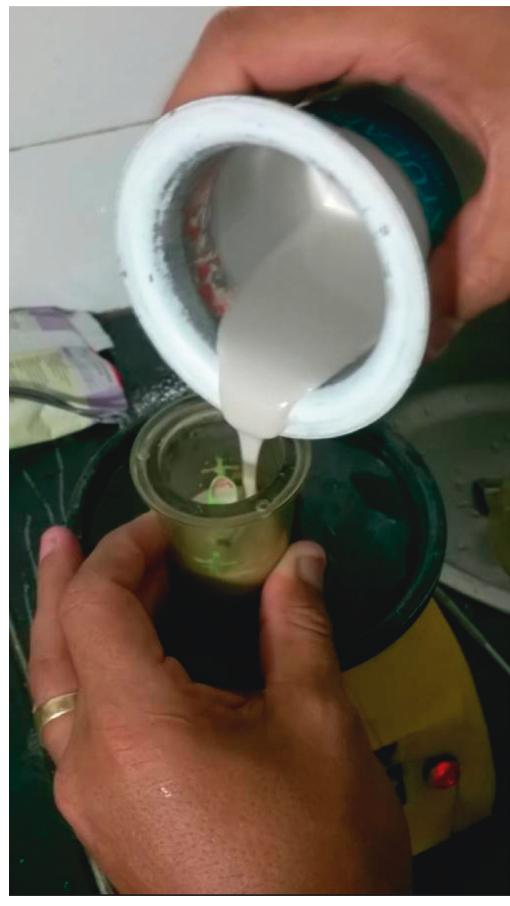

(c)
FIGURE 12: Laboratory steps for manufacturing of ceramic laminates. (a) Fixation of the waxed veneers at the base, (b) adaptation of the silicone ring at the base, and (c) addition of the coating liquid.

oral rehabilitation, correct diagnosis, treatment plan, and the type of material to be used in the selected treatment.

In the Brazilian population, the prevalence of dental agenesis varies in percentage, depending on the study. The values found were $29.5 \%, 7.9 \%$, and $2.9 \%$ in which agenesis of the third molar is the most common [13]. Opinions vary on the second most commonly affected tooth; some studies show that the second lower premolar has the highest in prevalence while others show that the superior lateral incisor has the highest $[1,3,5,13]$.

The treatment of dental anomalies is always a challenge for the general practitioner. For Alavi et al. [25] and Giordano [28], the best method would be the use of composite resin owing to the preservation of dental structure and the financial cost. For Nathanson and Riis [26], Giordano [28], Van Dijken [29], and Höland et al. [30], ceramic restorative materials would be the best choice since composite restorations undergo time action and require regular 


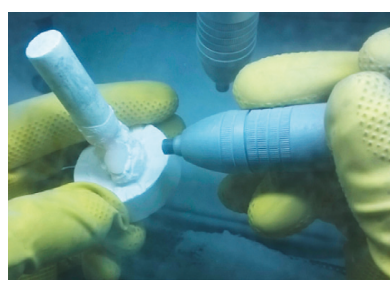

(a)

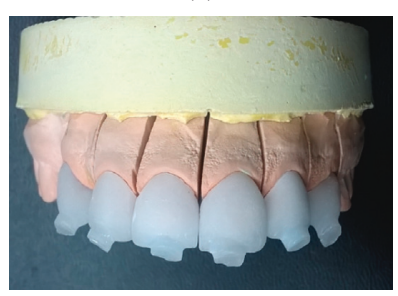

(b)

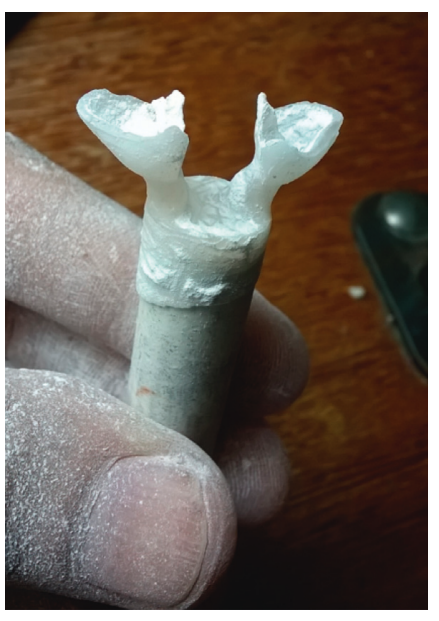

(c)
FIgURE 13: (a) Removal of the laminates from the coating mold using shot blasting with glass microspheres; (b) ceramic pieces placed in the plaster model, still with the remnants of the feed channels; (c) view of the injected parts attached to feed channels.

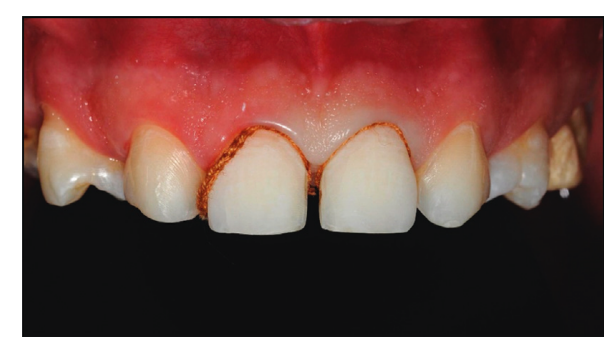

FIgURE 14: Gingival clearance prior to cementation.

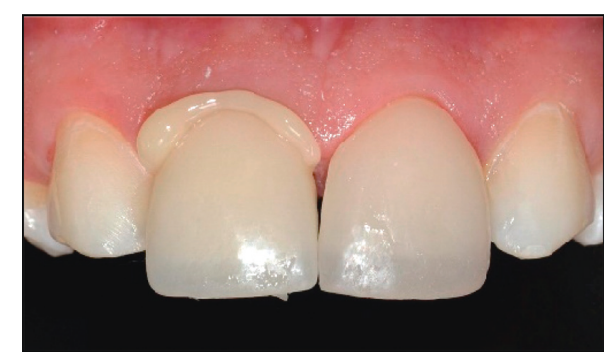

Figure 15: Extravasation of the cementing agent in element 11.

maintenance. In addition, composite resins exhibit lower clinical longevity due to greater susceptibility to pigmentation and marginal fractures [33].

In this clinical report, the use of ceramic laminates was the treatment of choice, in particular, the ceramic system VITA PM-9 because this material presents the following advantages: ability to reproduce the appearance of natural teeth, good translucency, excellent resistance, and similar biomechanical behavior to the tooth structure.

Nowadays the treatment with ceramic laminates rehabilitation is in use in a large scale; this is mainly due to being a very conservative treatment, where the wear of the dental element is minimal preserving the dental structure, especially in young patients [22-32]. However, because they

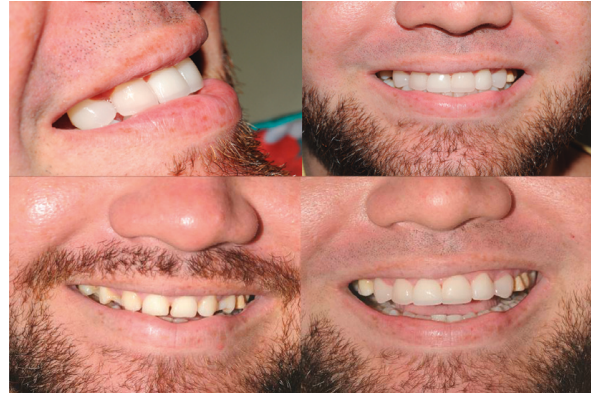

FIgURE 16: Final result.

are relatively recent techniques, they still do not have a common sense, mainly regarding their indications and limitations $[3,4,11]$.

Machry [34] affirms that one must always keep in mind the correct diagnosis to carry out a correct planning and, consequently, an appropriate treatment sequence for each case. Although recent, clinical evaluations have shown a very promising outlook, today they represent an alternative that the clinician needs to employ in selected cases.

\section{Conclusion}

The diversity of ceramic systems currently available in the world market is due to the increasing search for aesthetic excellence. The systems present advantages and disadvantages when compared to each other.

The most important in clinical cases is to establish a careful and realistic treatment plan, taking into account the patient's wishes. The time factor is often determinant for the selection of the treatment plan, since some patients want to solve their problem in the shortest time possible.

Thus, it can be concluded that the performed procedure corresponded very well with expectations of the patient and that the techniques used to do so were well performed, and it was obtained a satisfactory result.

\section{Conflicts of Interest}

The authors declare that there are no conflicts of interest regarding the publication of this paper.

\section{Authors' Contributions}

Ana Cássia de Souza Reis was responsible for study design, manuscript writing, critical review, and final approval; Ana Cristina Néry Normandes and Georgia Marques da Silva performed bibliographic survey, research, and selection of articles from PubMed and Bireme databases; Fernanda Ferreira de Albuquerque Jassé and Lucas Alves Moura wrote and proofread the English language; Edson de Sousa Barros Júnior was responsible for the laboratory stages; Joyce Figueira de Araujo was responsible for preparation and writing of the manuscript; Kalena de Melo Maranhão was responsible for conception, design of the study, preparation, writing of the manuscript, and final approval; and Thaís Andrade de Figueiredo Barros was responsible for the clinical stages and general coordination of the work. 


\section{References}

[1] E. Argyropoulos and G. Payne, "Techniques for improving orthodontic results in the treatment of missing maxillary lateral incisors. A case report with literature review," American Journal of Orthodontics and Dentofacial Orthopedics, vol. 94 , no. 2, pp. 150-165, 1988.

[2] B. J. Millar and N. G. Taylor, "Lateral thinking: the management of missing upper lateral incisors," British Dental Journal, vol. 179, no. 3, pp. 99-106, 1995.

[3] R. Sabri, "Management of missing maxillary lateral incisors," Journal of the American Dental Association, vol. 130, no. 1, pp. 80-84, 1999.

[4] G. Richardson and K. A. Russell, "Congenitally missing maxillary lateral incisors and orthodontic treatment considerations for the single-tooth implant," Journal-Canadian Dental Association, vol. 67, no. 1, pp. 25-28, 2001.

[5] V. O. Kokich Jr. and G. A. Kinzer, "Managing congenitally missing lateral incisors. Part I: Canine substitution," Journal of Esthetic and Restorative Dentistry, vol. 17, no. 1, pp. 5-10, 2005.

[6] R. Sabri and N. Aboujaoude, "Agenesis of the maxillary lateral incisors: orthodontic and implant approach," L'Orthodontie Française, vol. 79, no. 4, pp. 283-293, 2008.

[7] J. H. Park, S. Okadakage, Y. Sato, Y. Akamatsu, and K. Tai, "Orthodontic treatment of a congenitally missing maxillary lateral incisor," Journal of Esthetic and Restorative Dentistry, vol. 22, no. 5, pp. 297-312, 2010.

[8] S. Kavadia, S. Papadiochou, I. Papadiochos, and L. Zafiriadis, "Agenesis of maxillary lateral incisors: a global overview of the clinical problem," Orthodontics, vol. 12, no. 4, pp. 296-317, 2011.

[9] A. Johal, C. Katsaros, and A. M. Kuijpers-Jagtman, "State of the science on controversial topics: missing maxillary lateral incisors-a report of the Angle Society of Europe 2012 meeting," Progress in Orthodontics, vol. 14, no. 20, pp. 14-20, 2013.

[10] B. Mummidi, C. H. Rao, A. L. Prasanna, M. Vijay, K. V. Reddy, and M. A. Raju, "Esthetic dentistry in patients with bilaterally missing maxillary lateral incisors: a multidisciplinary case report," Journal of Contemporary Dental Practice, vol. 14, no. 2, pp. 348-354, 2013.

[11] R. R. Almeida, A. C. F. Morandini, R. R. Almeida-Pedrin, M. R. Almeida, R. C. F. R. Castro, and N. M. Insabralde, "A multidisciplinary treatment congenitally missing maxillary lateral incisors: a 14-year follow-up case report," Journal of Applied Oral Science, vol. 22, no. 5, pp. 465-471, 2014.

[12] A. Agrawal, N. Jain, N. P. Jose, and S. Shetty, "Interdisciplinary approach for management of congenitally missing maxillary lateral incisors: a case report," International Journal of Orthodontics, vol. 26, no. 4, pp. 15-17, 2015.

[13] P. A. Santos, "Tratamento de Ausência Congênita de Incisivo Lateral Superior por meio de Recuperação de Espaço para colocação de Implante Dentário ou Fechamento de Espaço, Relato de Casos," Revista Dental Press Ortodontia e Ortopedia Facial, vol. 7, no. 3, pp. 65-77, 2002.

[14] M. Rosa, A. Olimpo, R. Fastuca, and A. Caprioglio, "Perceptions of dental professionals and laypeople to altered dental esthetics in cases with congenitally missing maxillary lateral incisors," Progress in Orthodontics, vol. 14, no. 1, p. 34, 2013.

[15] M. Rosa and B. U. Zachrisson, Integrating Esthetic Dentistry and Space Closure in Patients with Missing Maxillary Lateral Incisors, vol. 1, no. 1, pp. 41-55, RClin Ortodon Dental Press, Maringá, Brazil, 2002.
[16] V. O. Kokich Jr., "Congenitally missing teeth: orthodontic management in the adolescent patient," American Journal of Orthodontics and Dentofacial Orthopedics, vol. 121, no. 6, pp. 594-595, 2002.

[17] B. U. Zachrisson, "Improving orthodontic results in cases with maxillary incisors missing," American Journal of Orthodontics, vol. 73, no. 3, pp. 274-289, 1978.

[18] E. Halley, "Direct composite veneers-an aesthetic alternative," Private Dentistry, vol. 20, 2012.

[19] A.-H. Muhamad, W. Nezar, A. Azzaldeen, and B. Musa, "Treatment of patients with congenitally missing lateral incisors: is an interdisciplinary task," Research and Reviews: Journal of Dental Science, vol. 2, no. 4, 2014.

[20] M. Fradeani, M. Redemagni, and M. Corrado, "Porcelain laminate veneers: 6- to 12-year clinical evaluation-a retrospective study," International Journal of Periodontics and Restorative Dentistry, vol. 25, no. 1, pp. 9-17, 2005.

[21] E. Öztürk and S. Bolay, "Survival of porcelain laminate veneers with different degrees of dentin exposure: 2-year clinical results," Journal of Adhesive Dentistry, vol. 16, no. 5, pp. 481-489, 2014.

[22] T. S. Liu and X. D. Chen, "Application of all-ceramic laminates veneer with Vita VM9 in clinic," Huaxi Kouqiang Yixue Zazhi, vol. 25, no. 5, pp. 447-449, 2007.

[23] S. Turgut and B. Bagis, "Colour stability of laminate veneers: an in vitro study," Journal of Dentistry, vol. 39, no. 3, pp. e57-e64, 2011.

[24] S. Turgut and B. Bagis, "Effect of resin cement and ceramic thickness on final color of laminate veneers: an in vitro study," Journal of Prosthetic Dentistry, vol. 109, no. 3, pp. 179-186, 2013.

[25] A. A. Alavi, Z. Behroozi, and F. Nik Eghbal, "The shear bond strength of porcelain laminate to prepared and unprepared anterior teeth," Journal of Dentistry, vol. 18, no. 1, pp. 50-55, 2017.

[26] D. Nathanson and D. Riis, "Advances and current research in ceramic restorative materials," Current Opinion in Cosmetic Dentistry, pp. 34-40, 1993.

[27] D. M. Schneider, "Differing porcelain syste ms," Current Opinion in Cosmetic Dentistry, pp. 107-113, 1995.

[28] R. A. Giordano, "Dental ceramic restorative systems," Compendium of Continuing Education in Dentistry, vol. 17, no. 8, pp. 779-782, 1996.

[29] J. W. Van Dijken, "All-ceramic restorations: classification and clinical evaluations," Compendium of Continuing Education in Dentistry, vol. 20, no. 12, pp. 1115-1124, 1999.

[30] W. Höland, M. Schweiger, R. Watzke, A. Peschke, and H. Kappert, "Ceramics as biomaterials for dental restoration," Expert Review of Medical Devices, vol. 5, no. 6, pp. 729-745, 2008.

[31] Y. H. Chun, C. Raffelt, H. Pfeiffer et al., "Restoring strength of incisors with veneers and full ceramic crowns," Journal of Adhesive Dentistry, vol. 12, no. 1, pp. 45-54, 2010.

[32] F. J. Burke, "Survival rates for porcelain laminate veneers with special reference to the effect of preparation in dentin: a literature review," Journal of Esthetic and Restorative Dentistry, vol. 24, no. 4, pp. 257-265, 2012.

[33] M. E. Miranda, K. A. Olivieri, F. J. Rigolin, and R. T. Basting, "Ceramic fragments and metal-free full crowns: a conservative esthetic option for closing diastemas and rehabilitating smiles," Operative Dentistry, vol. 38, no. 6, pp. 567-571, 2013.

[34] L. Machry, Facetas Em Porcelanas. $44 f$. Trabalho de Conclusão de Curso (Especialização em Dentística Restauradora), Escola Aperfeiçoamento Profissional-ABO-SC, Florianópolis, Brazil, 2003. 


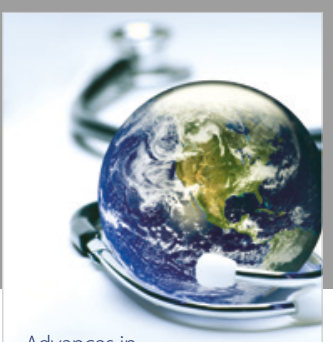

Advances in
Public Health

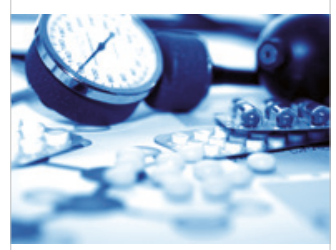

Case Reports in

Medicine

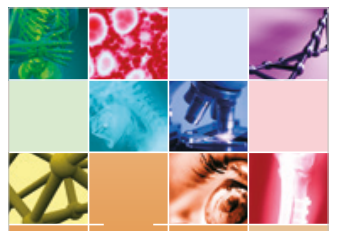

niernational Journal of

Biomaterials
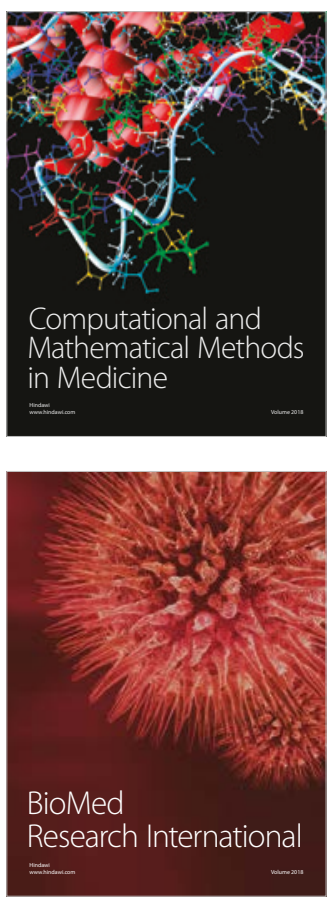

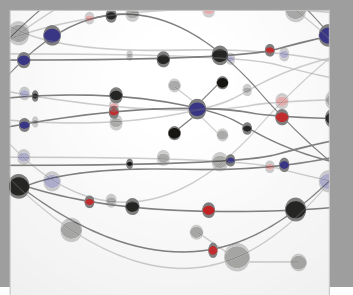

The Scientific World Journal Dentistry

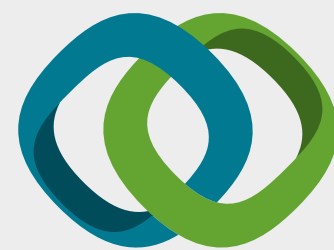

Hindawi

Submit your manuscripts at

www.hindawi.com
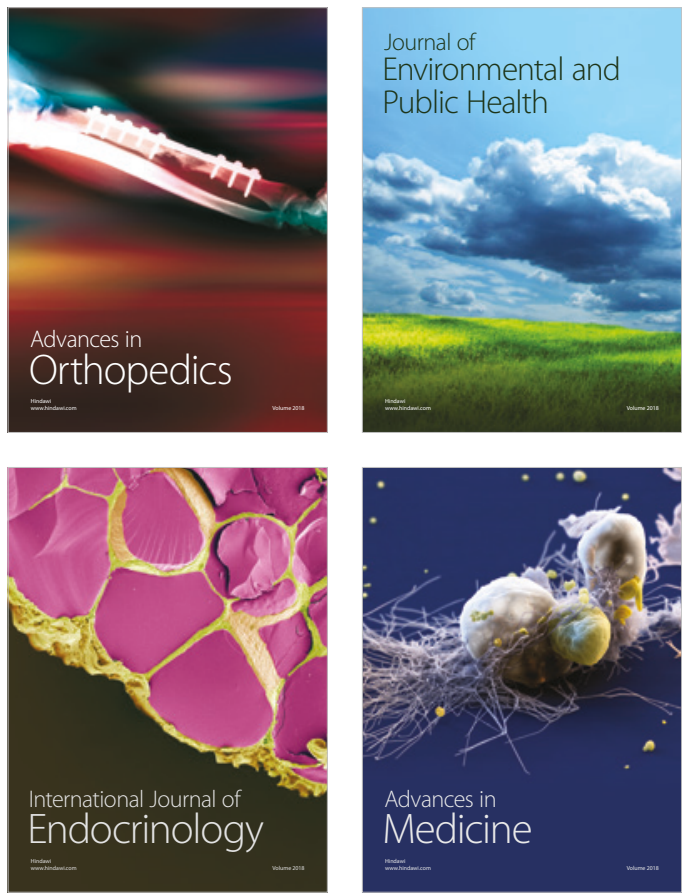
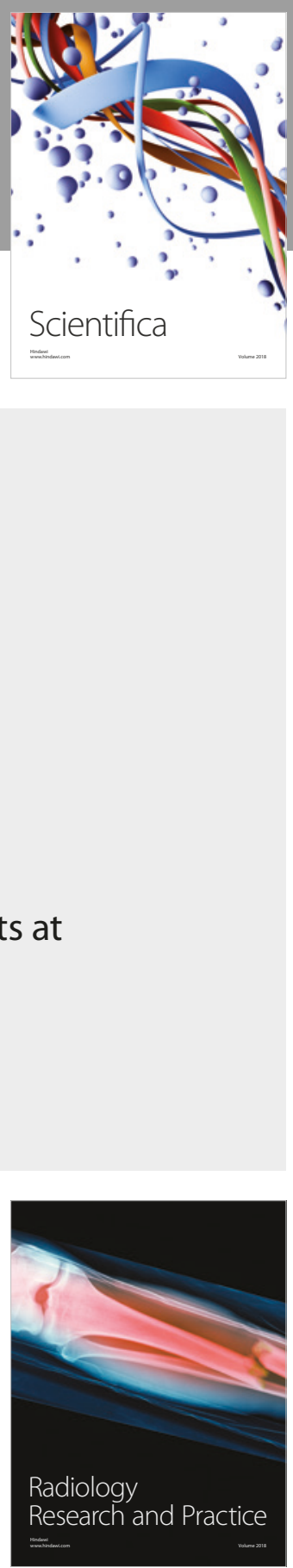

Scientifica

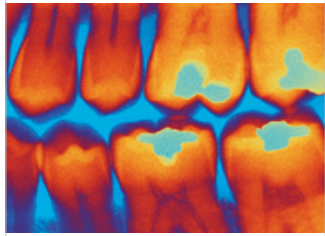

Case Reports in

Dentistry
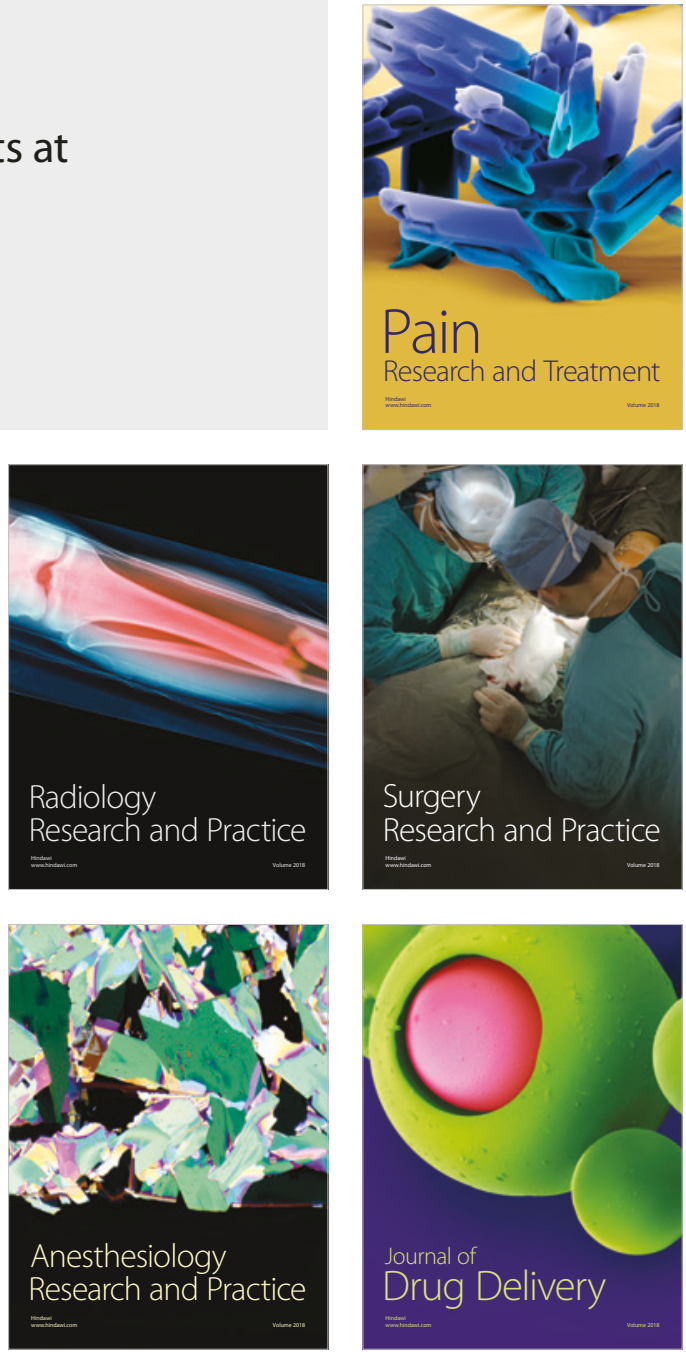